\title{
Prospecting for Groundwater Using the Continuous Vertical Electrical Sounding Method
}

\author{
Mohammed Mansuru Issah \\ Akwasi Acheampong Aning \\ Reginald Mensah Noye \\ Department of Physics, Kwame Nkrumah University of Science and \\ Technology, Kumasi, Ghana \\ Patrick Amankwaa Mainoo \\ Water Research Institute(WRI),Council for Scientific and Industrial \\ Research(CSIR), Accra, Ghana
}

Doi: 10.19044/esj.2018.v14n3p67 URL:http://dx.doi.org/10.19044/esj.2018.v14n3p67

\begin{abstract}
2-D CVES surveys using the Wenner configuration was carried out in 22 communities in the Tain District, Ghana. This was done with the objectives of assessing the subsurface geology, identify high groundwater potential zones for drilling high-yielding boreholes that could yield sustainable amount of groundwater. The collected resistivity data were converted from the apparent resistivity to 2-D model section using the least-square inversion algorithm with the help of Res2DInv software. The 2-D resistivity model-sections produced a high quality structural resolution leading to the demarcation of the layering of various lithological units, weathered layers and identification of important structures such as joints, fractures and faults. Quantitatively, it can be observed that all the drilled wet wells have aquifer zones between $30 \mathrm{~m}$ and $60 \mathrm{~m}$ within sandstone, siltstone and phyllite granitic environments. The result of the borehole drill $\operatorname{logs}$ revealed that the aquifers were within weathered and fractured zones and is in agreement with the models. The results showed that the boreholes yield within the study area varied between a minimum of 15 litres/min to a maximum 800 litres/min and the mean depth for intercepting aquifer was at about $30 \mathrm{~m}$ and below. The study revealed that the potential aquifer zones in the study area are mostly as a result of weathering of the overburden and fracturing of the underlying bedrock. The results suggest that the hydrogeology of the study area is highly complex since the development of groundwater is generally due to secondary porosities.
\end{abstract}

Keywords: Groundwater, 2-D CVES, apparent resistivity, borehole 


\section{Introduction}

In spite of water being basic necessity for life, many parts of the world, especially in developing countries including Ghana, sees it as a challenge to come across potable water. Most rural settlements have generally depended on various surface water sources such as lakes, streams, dug-outs and impoundment repositories. Some of these surface water sources are intensely polluted, bringing about water-borne and water-related maladies, for example, diarrhoea, guinea worm, bilharzia, and so forth. (Gyau-Boakye et al., 2008). Water is very important to life, however it can and does transmit infections in nations - from the deprived to the richest. The key leading waterborne disease, diarrhoea, has a projected yearly frequency of 4.6 billion occurrences and causes 2.2 million deaths annually (WHO, 2010).

The accessibility of quality water has been the essential concern of rural communities in Ghana and all over Africa. The issue of acquiring a sufficient supply of potable water is becoming increasingly difficult as a result of increasing population which is resulting in increasing industrialization and agricultural activities. Hence, there is the quest for other alternatives to supplement the surface water to sustain the increasing demand from population and industrialization activities. This makes the world to depend on one of the largest available source of quality fresh water which lies underground and this is referred to as groundwater. Subsurface openings large enough to yield water in a usable quantity to wells and springs underlie nearly every place on the land surface and thus making groundwater one of the most widely available natural resources (Heath, 1987).

Although groundwater is a hidden resource, geophysical and geological principles can help specialists locate groundwater supplies and to delineate zones where no groundwater supplies are available but have not been explored. Groundwater is accumulated and stored underneath the surface in geologic structures in rocks called aquifers. Groundwater sources are the largely reliable resource for use as drinking-water in most parts of the world, especially in areas with restricted or contaminated surface water sources. This is in the light of the fact that groundwater is normally of good quality relative to surface water sources. Thus, it almost does not need treatment before drinking, although surface waters by and large must be treated (WHO, 2006).

Throughout Ghana, groundwater sources appear to be important source of water supply systems mostly used for domestic purposes. About $70 \%$ of Ghana's population greatly depend on groundwater for drinking purposes (Kortatsi et al., 2008) and the nature of groundwater asset is pivotal to giving the required requests to household, irrigation and industrial purposes (Anornul et al., 2012).

Undoubtedly, the beneficial utilization of water for residential purposes cannot be recognized at the household level, especially among poor 
urban communities. Likewise, there may be important wellbeing and social gains from guaranteed sufficient quality supply to help small-scale usage or utilization, for instance where this includes food production. Access to sufficient water supply for small-scale industries in such regions is thus vital as a major aspect of poverty alleviation, and may convey noteworthy health benefits as well (WHO, 2010).

\section{2-D Continuous Vertical Electrical Sounding (CVES)}

In conventional resistivity techniques, the horizontal electrical profiling (HEP) measures only variation in resistivity with lateral extent of the subsurface as anomalies beneath the profiles. However, vertical electrical sounding (VES) measures only variation and discontinuity in resistivity with depth as recognisable anomalies beneath the profiles. CVES technique simultaneously studies both vertical and lateral distribution of resistivity beneath the whole profile. This particular resistivity technique helps to detect water-bearing zones between two points of survey. The two dimensional (2D) data generated using multi-electrodes results in high density pseudosections with dense sampling of apparent resistivity measurements at shallow depth ranging from surface to a depth of $300 \mathrm{~m}$ in a short time (Dewashish, 2012). The ERI method is comprehensively used in groundwater exploitation, environmental and geotechnical studies (Ratnakumari et al., 2012).

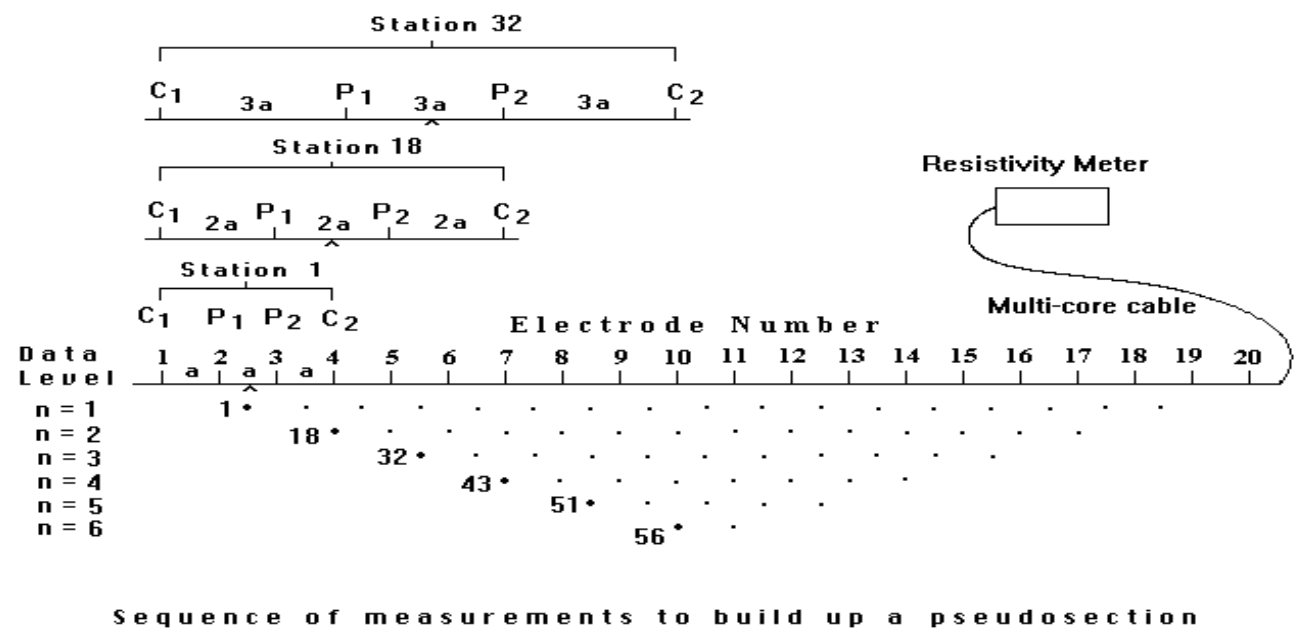

Figure 1. Schematic diagram showing the arrangement of electrodes for a 2-D electrical survey and the sequence of measurements for building up a pseudosection (Loke, 2010)

ERI is mostly carried out using a large number of equally spaced collinear array of electrodes connected to a multi-core cable. The separation between the potential electrode and the current electrodes depends on the electrode configuration. A laptop computer coupled with an electronic switching unit is used to automatically select the relevant electrodes to be used 
as potential electrode pair and current electrode pair for each measurement. Figure 1.0 illustrates a potential arrangement of measurements for the Wenner electrode configuration for a system with 20 electrodes.

\section{Geology and Hydrogeology}

The Tain District (Figure 2.0) is located at North West of Sunyani. It lies within latitudes 7.555 N and 8.204 N North and longitudes 2.007 West and 2.784 West. The district shares common boundaries with Jaman North to the west, Wenchi Municipal to the east, Sunyani Municipal to the south and Berekum Municipal to the south-west. It is also bounded by the Bole District of the Northern Region to the north east and La Cote d'Ivoire to the north-west (Tain District Assembly, 2006).

The area falls under Birimian and Tarkwain rocks formations. The Birimian is the most mineralised formation in the country and comprises very thick isoclinal folds and metamorphic sediments. The area is underlain by collapsed schists, greenstones, phyllites and greywackes. The intrusive granitoids of this formation are very important in groundwater resources as they contain secondary discontinuities like fractures, joints etc. and therefore form permeable groundwater reservoirs (Amoako, 2008). The Tarkwain is made of meta-sediment rocks i.e. conglomerate, sandstone, quartzite and shale. The Tarkwain is derived from the Birimiam (metavolcanics) as a result of Eburnean tectono-thermal event; an orogenic activity. These rocks develop secondary and tertiary porosities and as a result accumulate substantial volume of water (Amoako, 2008). The region is underlain by folded phyllites, schists, greenstones and greywackes and gives it suitable conditions for groundwater accumulation and storage. These properties are positive for geophysical investigations, borehole prospects and comprehensive hydrogeological mapping (Erdelyi, 2010). 


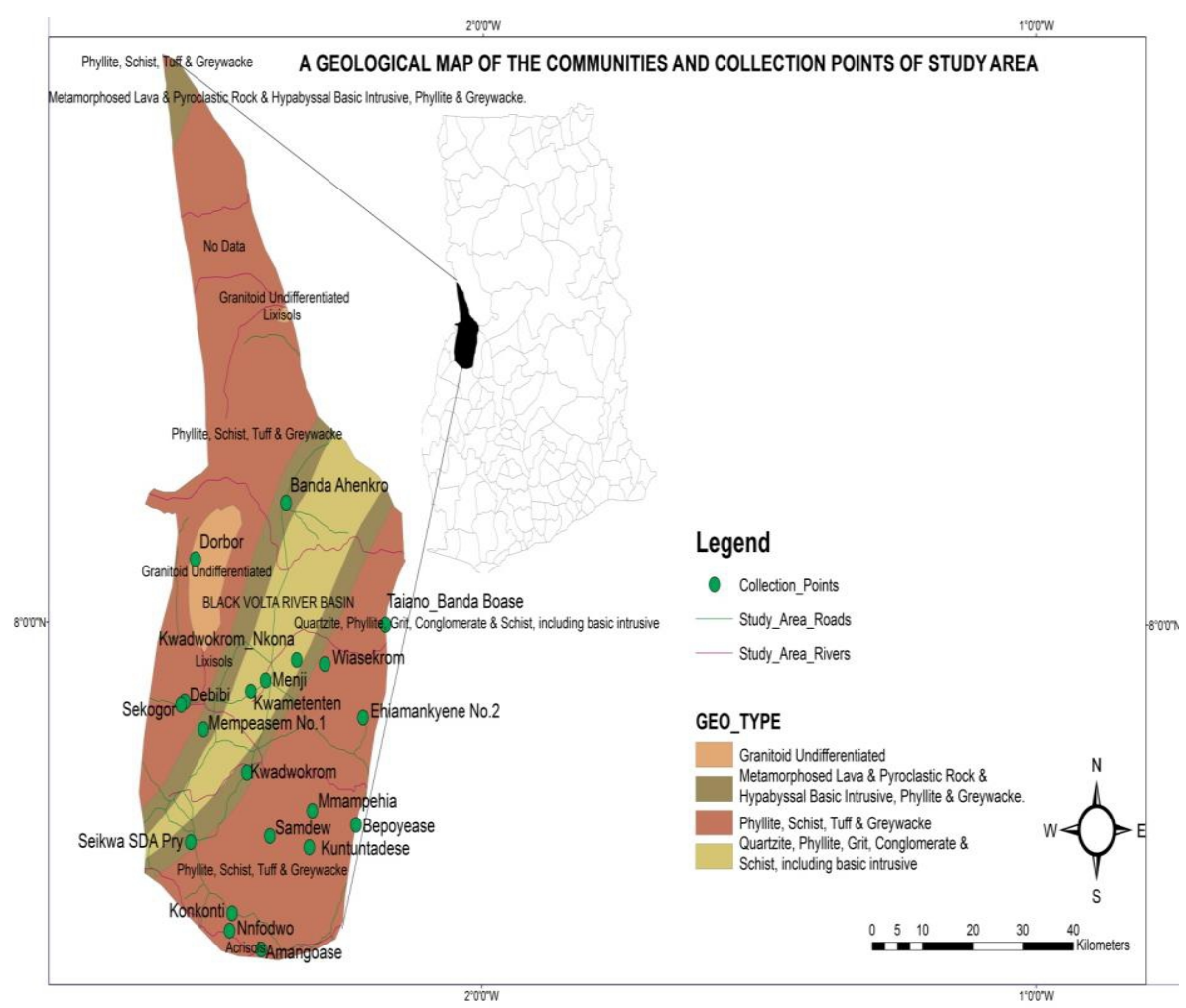

Figure 2. Geological Map of Tain District showing communities

With the exception of Menji and Kwametenten, which are underlain by Tarkwain rocks, the rest of the project communities in the district are underlain by rocks associated with the Birimian Formation. The Birimian rocks are highly folded, generally foliated and fractured (Gill, 1969). A hydrogeological assessment conducted on the hydrogeologic province and sub-provines in Ghana indicated that boreholes drilled in the Birimian sediments had yields varying between $0.41-29.8 \mathrm{~m}^{3} / \mathrm{h}$ with a mean yield of $17.3 \mathrm{~m}^{3} / \mathrm{h}$. Similarly, aquifer systems associated with the Tarkwain formation had borehole yields varying within $0.45-23.6 \mathrm{~m}^{3} / \mathrm{h}$ with an average borehole yield of $7.4 \mathrm{~m}^{3} / \mathrm{h}$ (Dapaah-Siakwan and Gyau-Boakye, 2000). However, with improved geophysical techniques to delineate groundwater potential zones, there is the tendency to drill high-yielding boreholes within these geologic units.

\section{Geophysical Field Survey}

The LUND resistivity survey technique was used for the 2D subsurface resistivity studies. This technique runs both profiling and vertical electrical sounding concurrently to produce a 2D high resolution resistivity pseudo-section output of the surface. The field procedure employed for the geo-electric imaging included laying out the 42 steel electrodes along the 
profile which was connected to the multicore cable at $5 \mathrm{~m}$ regular take-out intervals via sets of cable jumpers. The measurement of the apparent resistivity of the subsurface was carried out by the electrode selector ES 464 and the SAS 4000 terrameter powered by $12 \mathrm{~V}$ accumulator. Measurements were possible after all the electrodes were connected via the take-outs; the terrameter and the electrode selector are coupled together along a symmetrical spread. GPS was also used for locating profile line.

Care was taken in the field to minimise the error in measurements by injecting appropriate current into the ground depending on the terrain. The electrode test was performed to check the possibility of current flowing through all the electrodes. Poor ground contact was improved by changing the position of the poor contact electrodes, and sometimes connecting additional electrodes take-out to get sufficient contact.

The terrameter routinely changes the electrodes to function as current and potential pairs for a protocol chosen for the measurement (Aning et al., 2013). A chosen protocol makes series of electrode combinations between the currents and potential electrodes to collect the data. Thus, measurements are automatically taken by the equipment and stored in the terrameter with the help of special electrode protocols selection. The data is automatically stored in files in the terrameter in binary formats.

\section{Data processing}

The recorded data for each profile from the LUND imaging survey was downloaded from the Terrameter via a communication cable onto a personal computer (Laptop). The downloaded data was then converted from *.s $\mathbf{4 k}$ into RES2DINV format (*.DAT format), which is compatible and can be read with the inversion software.

Bad data points were effectively identified as they showed up and exterminated with the aid of the software. In addition the RES2DINV software was used to remove negative resistivity readings, extremely high and low resistivity readings from the data set before the resulting data were inverted. The elimination of the bad data points is necessary because it affects the data quality. Such erroneous resistivity values might be as a result of bad electrodeground contact along the profile because of the dryness of the top layer, shorting across the electrical cables as a result of moisty ground situations and malfunctioning of some of the electrodes (Geotomo Software, 2010).

The geo-electrical resistivity inversion software was then used to carry out the inversion to produce $2 \mathrm{D}$ resistivity model-sections. The inversion routine used by the program is based on the smoothness constrained least square technique (Loke, 2000). The inversion program uses both finitedifferences and finite-element forward modelling technique. A forward modelling subroutine is used to calculate the apparent resistivity values, and a 
non-linear least- squares methods based on a quasi-Newton optimization method techniques is used for the inversion routine (Geotomo Software, 2010). Model refinement was used to get optimum results as the option permits the selection of models with widths of half electrode spacing which was very significant due to the fact that it aided resolving changes in the close surface that might cause misrepresentations in the lower section of the model (Aning et al., 2013).

Sharp variations in the resistivity values was reduced with the help of the robust inversion constrain technique which lead to the production of model-sections with sharp boundaries among different zones with dissimilar resistivity values, but having virtually unvarying resistivity value within individual zones (Geotomo Software, 2010). RES2DINV automatically creates a 2D model-section which provides true resistivity variation of the subsurface (Ratnakumari et al., 2012).

\section{Results and Discussion}

The 2D CVES (model -sections) produced has direct correlation to sub-surface geologic layers. The analysis and interpretation of the resistivity models are therefore based on the knowledge of geology of the project area. The interpretation leads to the knowledge of the maximum depth at which it would be likely for groundwater to occur (Sabet, 1975). The profile lines (resistivity model-sections) figures 3.0 to 12.0 were named after the communities from which they were acquired. For uniformity in the analysis and interpretation of resistivity pseudo-sections along the various profile lines, each profile data was processed separately. However, similar inversion procedures were employed in the processing of the entire model-sections. This helped to reduce differences and ambiguity to the minimum degree.

In the analysis and interpretation of the 2-D resistivity model-sections, important consideration was given to the electrical resistivity values and not the colour representation because the same colour on each of the profiles in each community represents different resistivity range of values. Variation in the layers is represented by the varying resistivity values of the formations, which is associated with the various colours in the model-sections.

The modelled 2D resistivity sections were analysed to delineate resistivity and depths of various geological materials along the various profiles investigated. The sections were interpreted using the thicknesses of the various layers along the profiles coupled with the local geological conditions to select suitable sites with high groundwater potential. 


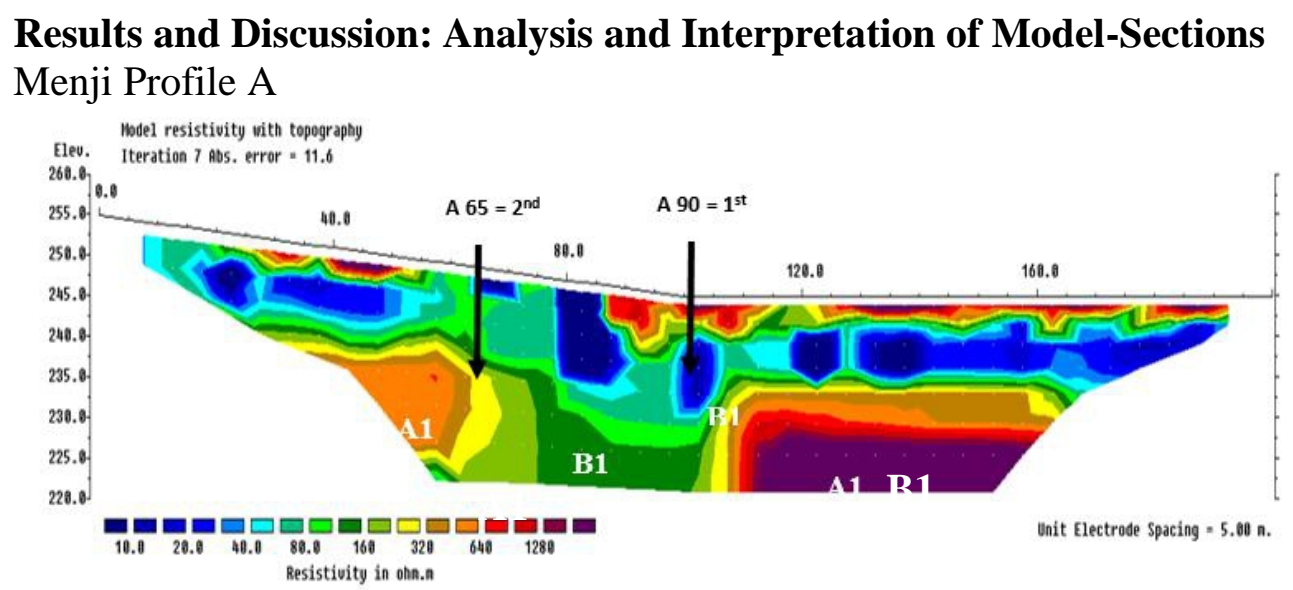

Figure 3. Resistivity model-section of Menji profile A

The model-section (Figure 3.0) depicts general varying low resistivity values $<80 \Omega \mathrm{m}$ from the surface up to a depth of about $15 \mathrm{~m}$, beneath the profile. The thin high electrical resistivity $>600 \Omega \mathrm{m}$ observed at isolated places on the model-section in the near surface could be attributed to lateritic gravel materials at the surface as part were clearly seen on the surface during the fieldwork.

The high resistive structures on this section with resistivity values $(600$ -1300) $\Omega \mathrm{m}$ labelled $\mathbf{A 1}$, at the base of the profile were interpreted as the basement rock. The low resistivity $<160 \Omega \mathrm{m}$ regions marked B1 which extend beneath at around 80 and $105 \mathrm{~m}$ is bounded by the relative high resistive structures. The sharp resistivity contrast was therefore interpreted as a fracture; hence zone B1 is good indication of possible geological structure, which could be a good aquifer for groundwater production. The points A90 and A65 marked $1^{\text {st }}$ and $2^{\text {nd }}$ were selected for drilling in the order of preference.

\section{Kwametenten profile}

The resistivity model-section (Figure 4.0) reveals a general disorderly long range of resistivity $6-850 \Omega \mathrm{m}$ beneath the length the profile indicating high degree of weathering and fracturing of the subsurface formation. The high resistive structures on this section with resistivity values between 200 and 400 $\Omega \mathrm{m}$ marked $\mathbf{C 1}$, in the near surface of the profile were interpreted as large masses of laterite as part were clearly seen on the surface. Also the very high resistivity (> $822 \Omega \mathrm{m}$ ) geological formation observed between of 90 to $100 \mathrm{~m}$ on the profile line between depth of $5 \mathrm{~m}$ and $10 \mathrm{~m}$ labelled $\mathbf{C 2}$ could be interpreted as a mass of hard compact rock. 


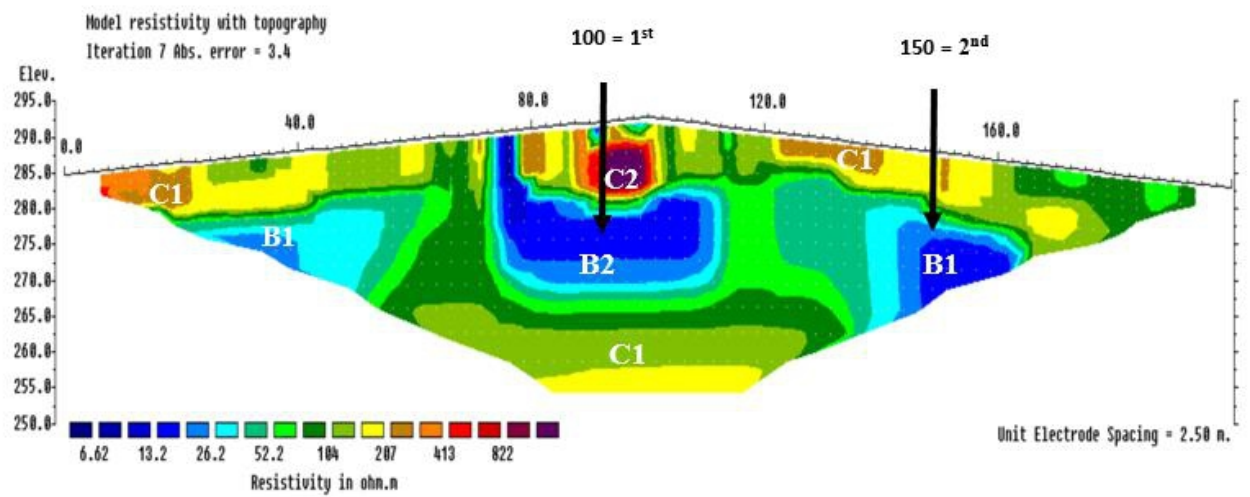

Figure 4. Resistivity model-section of Kwametenten profile B

The portions labelled $\mathbf{B} 1$ and $\mathbf{B} 2$ are low resistivity $(<30 \Omega \mathrm{m})$ geological anomaly bounded with relatively high resistivity zones. These regions were interpreted as a weathered fracture and a good indication of water accumulation within these formations due to the lithological changes and possible good aquifers for groundwater storage. B2 is located within the fractured basement rock formation and interpreted as possible good formation for aquifer (basement aquifers) and groundwater accumulation and was therefore selected for drilling. Based on the geological formation, the points B100 and B150 marked $1^{\text {st }}$ and $2^{\text {nd }}$ were selected for drilling in the order of preference.

\section{Debibi (Health Centre) profile}

The model-section (Figure 5.0) reveals varying low resistivity values $<40 \Omega \mathrm{m}$ from the surface up to a depth of about $8 \mathrm{~m}$ beneath the profile, which constitutes the saturated weathered top layer. The resistivity model shows distinct degree of weathering and deformation of layers of rock which are clearly defined by their different resistivities between 75 and $160 \mathrm{~m}$ along the profile with the resistivity values fluctuating toward the end of the profile line. This weathered deformed material suggests a potential and promising site for groundwater as a result of its lithological nature. 


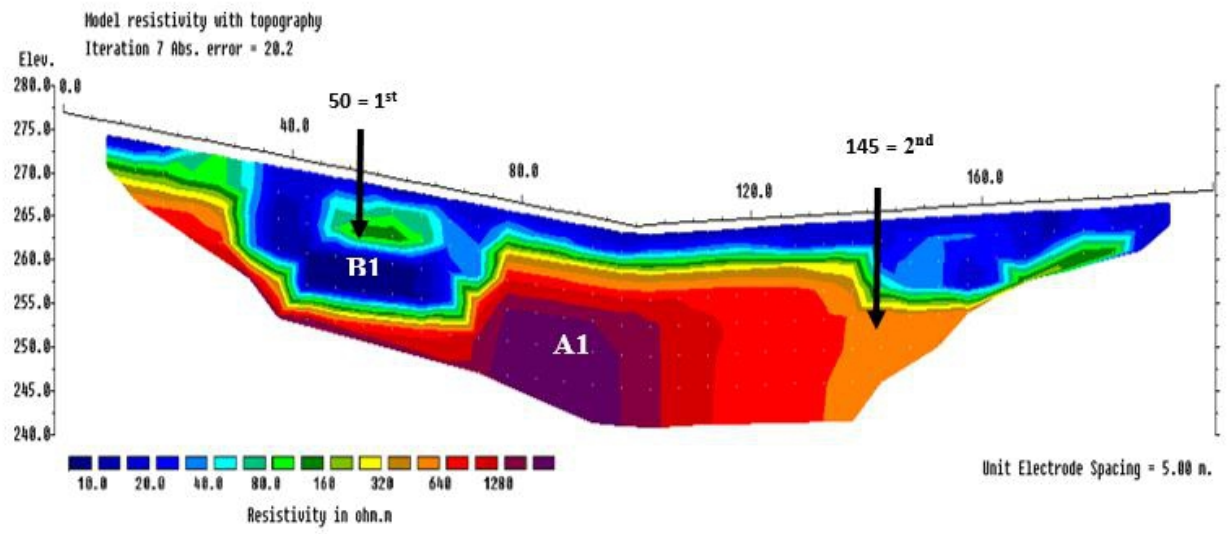

Figure 5. Resistivity model-section of Debibi (Heath centre) profile

The high resistivity zone of resistivity $>700 \Omega \mathrm{m}$ labelled $\mathbf{A 1}$ at the base of this model section is interpreted as semi-weathered bedrock. The thick low resistivity layer with resistivity value $<40 \Omega \mathrm{m}$ geological anomaly marked B1 observed between 30 and $75 \mathrm{~m}$ beneath the profile and extends down to depth of about $25 \mathrm{~m}$. This structure is engulfed by relatively higher resistive zones. This anomalous geological structure is located within the fractured basement rock formation and interpreted as possible good formation for aquifer (basement aquifers) and groundwater accumulation and was therefore selected for drilling. The points A50 and A145 marked $1^{\text {st }}$ and $2^{\text {nd }}$ were selected for drilling in that order of preference.

\section{Sekogor profile}

The top layer is highly-heterogeneous showing resistivity of about 5 to $178 \Omega \mathrm{m}$ throughout the profile up to a depth of about $2 \mathrm{~m}$ as clearly seen on the model-section (Figure 6.0) indicating weathering. The moderately-high resistivity materials only limited to the surface of the profile could be a case of lateritic gravel materials at the surface.

The top layer is underlain by comparatively low resistivity $<30 \Omega \mathrm{m}$ layer between the depths of 2 and $12 \mathrm{~m}$ beneath the profile, indicating highlyweathered saturated zone. This could be aquifer but may not be a good potential source for groundwater production. This could explain why the existing borehole drilled to a depth of $50 \mathrm{~m}$ along the profile line is not productive. 


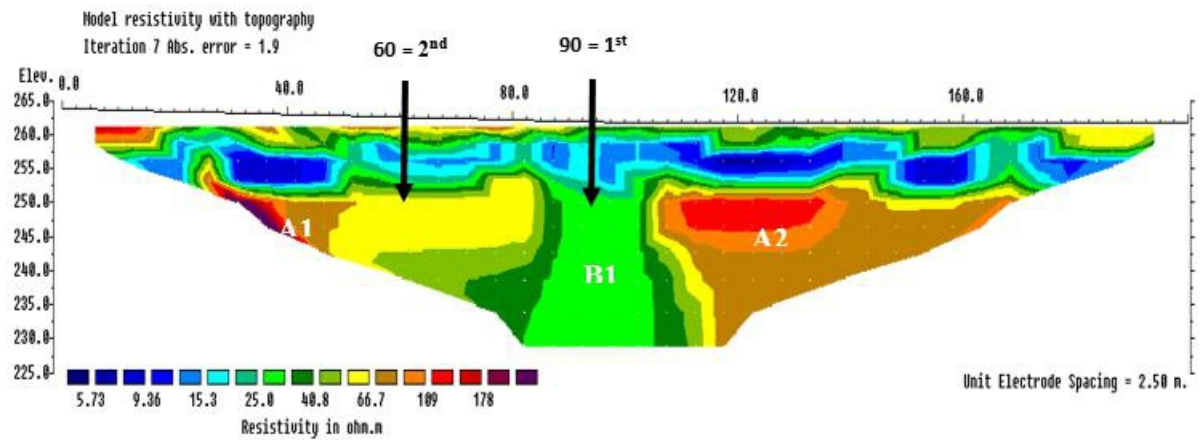

Figure 6. Resistivity model-section of Sekogor profile

There are high resistivity zones labelled $\mathbf{A 1}$ and $\mathbf{A 2}$ extending below the depth of resolution of the equipment on this section with varying resistivity values. The variation in the resistivity of region between portions marked A1 and B1 signifies varying degree of fracturing, which is a good indication of water flow within this formation due to the lithological changes and possible good aquifers for groundwater accumulation. The resistivity model-section shows a thick resistivity $25-45 \Omega \mathrm{m}$ structure marked B1 between moderately high resistivity regions at about 90 and $105 \mathrm{~m}$ along the profile. This is interpreted as a fracture and could therefore be a good aquifer to target for siting borehole. Based on the geological formation, the points A90 and A60 marked $1^{\text {st }}$ and $2^{\text {nd }}$ were selected for drilling in the order of preference.

\section{Mmaampehia profile}

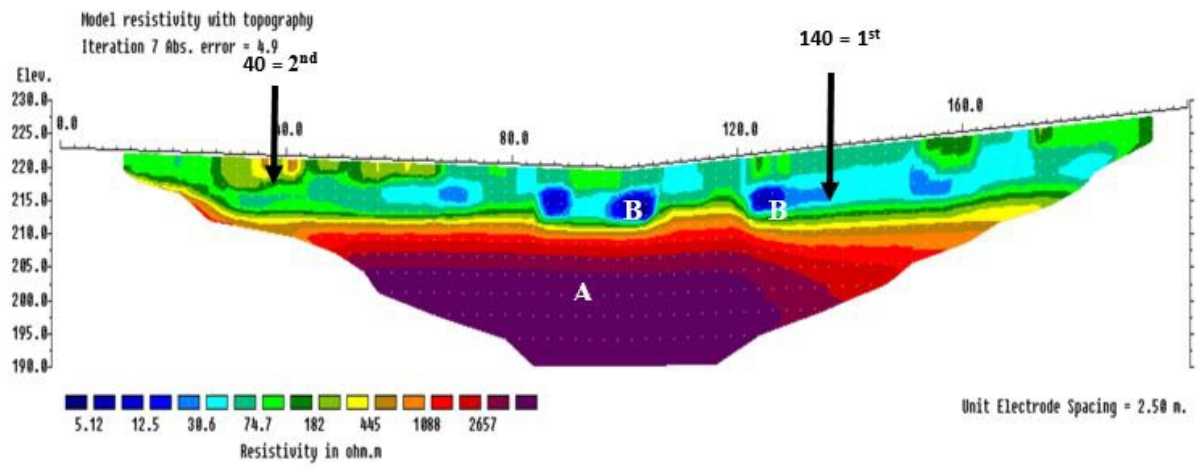

Figure 7. Resistivity model-section of Mmaampehia profile

The model-section (Figure 7.0) produces three different geological layered rock which are clearly defined by their different resistivity layers at the various depths. The model-section displays wide range of resistivity values from 5 to $450 \Omega \mathrm{m}$ to depth of about $10 \mathrm{~m}$ from the surface. This layer can be interpreted as highly heterogeneous soil formation derived from intense 
weathering of the underlying rock material. The model-section further reveals portions of low resistivity $<30 \Omega \mathrm{m}$ zones designated $\mathbf{B}$ found at isolated places within weathered top soil formation which can be interpreted as conductive isolated rock pockets.

The intermediate layer shows different subsurface materials with moderate resistivity with small changes in resistivity in the range 182 to 2000 $\Omega \mathrm{m}$ at depth of about 15 to $25 \mathrm{~m}$. This layer also appears broader between 30 - $60 \mathrm{~m}$ and 120 - $170 \mathrm{~m}$ along the profile line and was interpreted to have undergone some deformation as observed from the pattern and was interpreted as conceivable aquifers target for groundwater accumulation.

There is dense high resistivity $>2657 \Omega \mathrm{m}$ layer denoted by $\mathrm{A}$ at the base of this model-section. This high resistivity rock layer possibly representing the fresh rock material with no structural patterns gives no indication of fractures and joints which are indications for aquifers. Despite the shallow overburden thickness, the points A40 and A140, marked as $1^{\text {st }}$ and $2^{\text {nd }}$ were selected drilling.

\section{Konkonti profile}

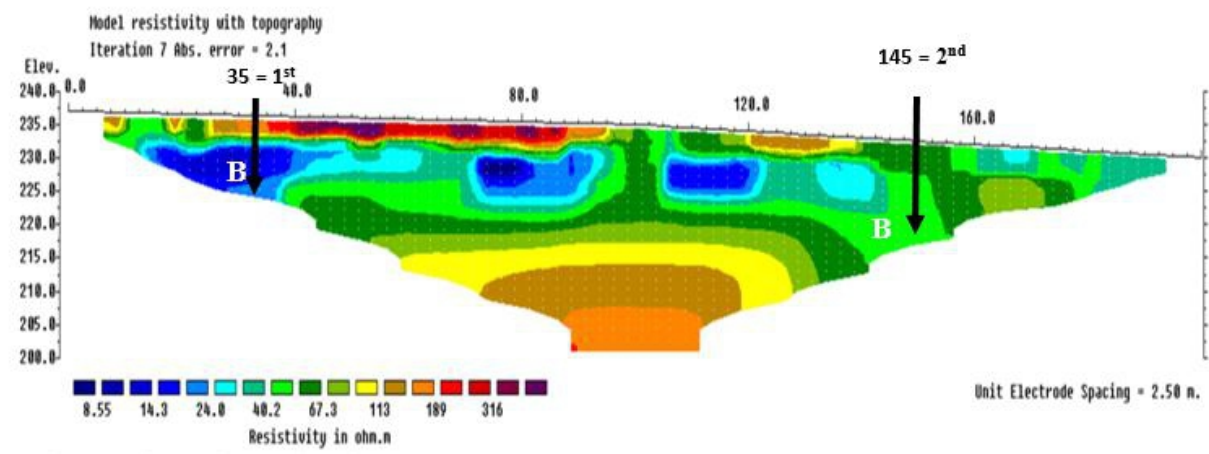

Figure 8. Resistivity model-section of Konkonti profile

The top surface is highly heterogeneous showing resistivity ranging from 8 to $320 \Omega \mathrm{m}$ to depth of about $15 \mathrm{~m}$ as clearly seen in (Figure 8.0) indicating highly-weathered top soil formation. The relatively-high electrical resistivity values 189 to $316 \Omega$ m observed in the near surface between 35 and $95 \mathrm{~m}$ could be lateritic gravel materials at the surface.

The model-section shows horizontal layers of different subsurface materials with small and sharp changes in resistivity at depth about $15 \mathrm{~m}$ to the base of the profile. These layers could be interpreted to be intercalations of different rock materials or showing the different weathered layers of rock at the subsurface.

There are regions with low resistivity $<40 \Omega \mathrm{m}$ tagged $\mathbf{B}$ below the resolution of the equipment between 15 and $35 \mathrm{~m}$ and between 140 and $150 \mathrm{~m}$ 
beneath the profile line. These regions reveal some degree of fracturing that could be interpreted as good material for an aquifer and was therefore selected for drilling. The points A35 and A145 marked $1^{\text {st }}$ and $2^{\text {nd }}$ were selected for drilling.

\section{Amangoase (Kyekyewere) profile}

The resistivity model-section (Figure 9.0) reveals varying high resistivity top layer ranging from (4 to $2000 \Omega \mathrm{m}$ to a depth of about $15 \mathrm{~m}$ indicating a high degree fractured and weathered top layer. This model-section exhibits a very high resistivity $>800 \Omega \mathrm{m}$ zone marked $\mathbf{A}$ in the left bottom the model-section, which is interpreted as bedrock. This high resistivity is also seen at the base of the profile at around $120 \mathrm{~m}$.

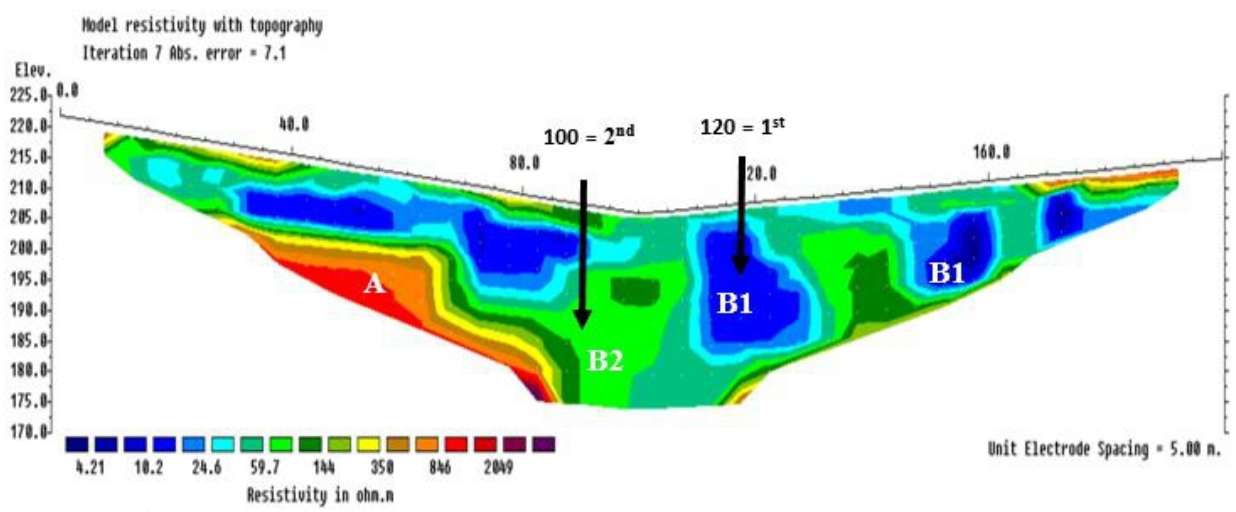

Figure 9. Resistivity model-section of Amangoase (Kyekyerewere) profile

Thick but low resistivity geological structural anomaly $(<25 \Omega \mathrm{m})$ overlain by relatively high resistivity zones labelled $\mathbf{B 1}$ is observed around 120 $\mathrm{m}$ along the profile line. This thick but low resistivity formation is interpreted as good aquifers for groundwater accumulation hence the region was selected for drilling. The resistivity model-section also shows a thick low resistivity of about $50 \Omega \mathrm{m}$ geological structure between moderately high resistivity zones marked B2 dipping downward at around $100 \mathrm{~m}$ along the profile line. The low resistivity zone could be fluid-filled or clay deposit. However, this is interpreted as a fracture and a good indication of water flow within these formations due to the lithological changes and depressive nature and possible aquifers for groundwater accumulation. The points A120 and A100 marked $1^{\text {st }}$ and $2^{\text {nd }}$ were selected for drilling in the order of preference.

\section{Seikwa profile}

Generally, the resistivity model-section (Figure 10.0) depicts a varying high resistivity top layer ranging from about 400 to $2000 \Omega \mathrm{m}$ to a depth of 
about $5 \mathrm{~m}$ suggesting the presence of lateritic material in top layer. Beneath this top layer is a thick layer of very low resistivity of about $9-20 \Omega \mathrm{m}$. This layer is bounded above by weathered sediments topmost layer and below by distinct layers of moderate resistivities.

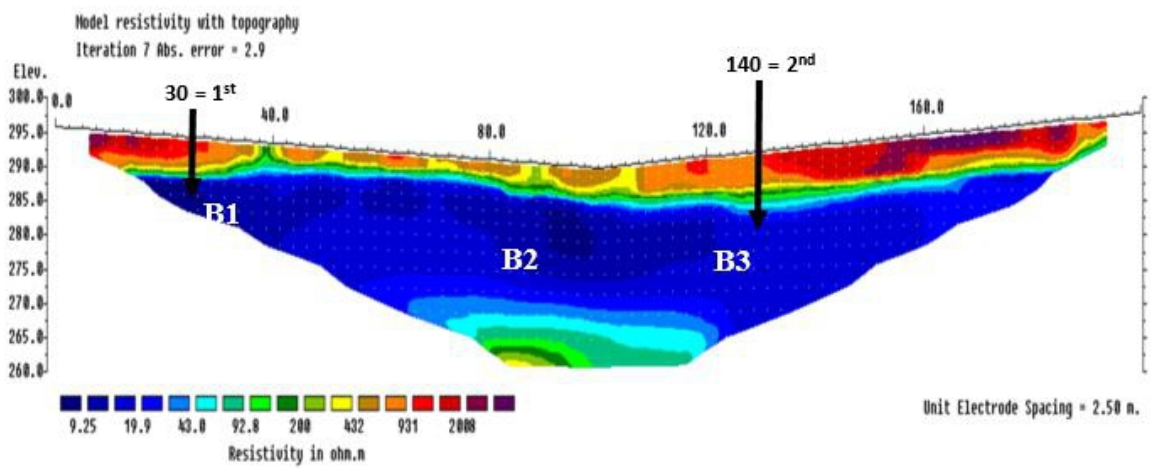

Figure 10. Resistivity model-section of Seikwa profile

Resistivity model-section shows zones of possible anomalies marked B1, B2 and B3 within the thick low resistivity zone. These spotted (anomalies) are bounded by relatively high resistivity region with quite lithological changes within formations and are interpreted as possible groundwater bearing zone. The points A30 and A95 marked $1^{\text {st }}$ and $2^{\text {nd }}$ were selected for drilling in the order of preference.

\section{Mempeasem profile}

The model-section (Figure 11.0) generally displays wide range of resistivity values from 1 to about $42 \Omega \mathrm{m}$ to a depth of about $10 \mathrm{~m}$ below the surface beneath the profile, which signifies high heterogeneous weathered top soil formation. Patches of very low resistivity values $<6 \Omega \mathrm{m}$ marked B observed at isolated locations within the weathered top layer could be moist clayey soil and may not be good aquifers for groundwater accumulation. The intermediate layer shows varying thin subsurface materials with moderate resistivity. However, there are small changes in resistivity in the range 12 $192 \Omega \mathrm{m}$ at depth of about $15 \mathrm{~m}$ between 40 and $160 \mathrm{~m}$, these may be an indication of intense weathering derived from the underlying rock material. 


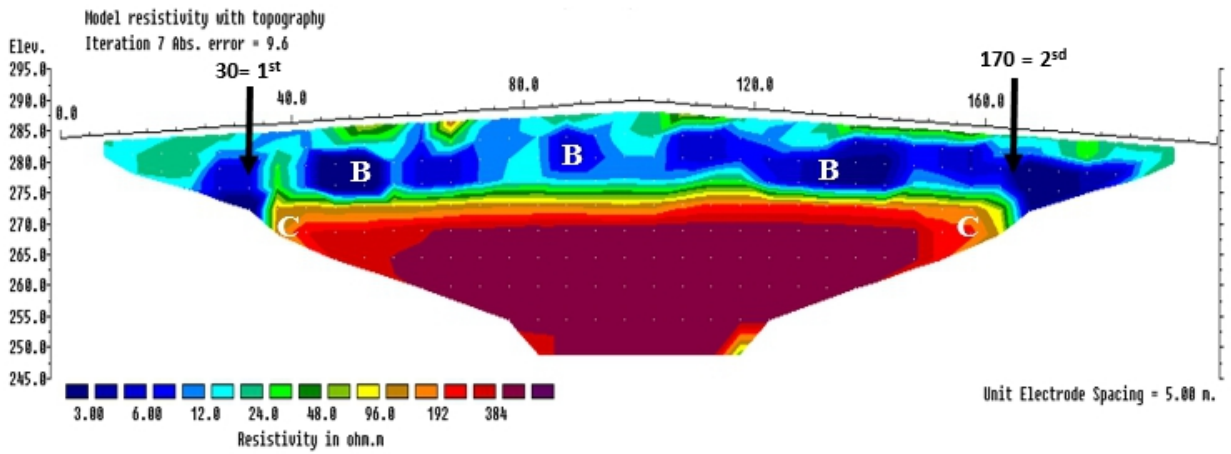

Figure 11. Resistivity model-section of Mempeasem profile

The resistivity model-section reveals differential vertical deformation and weathering associated with the host rock especially near the contacts around 40 and $160 \mathrm{~m}$. Such areas are hydrogeologically potential sites for good aquifers for groundwater accumulation for groundwater exploration. These regions are denoted $\mathbf{C}$ on the model-section. The points A30 and A170 marked $1^{\text {st }}$ and $2^{\text {nd }}$ are the selected potential aquifer site for drilling in the order of preference.

\section{Kuntuntadease profile}

The model-section (Figure 12.0) shows varying high resistivity geological layer with resistivity values with resistivity values higher than 400 $\Omega \mathrm{m}$ from the surface up to a depth of about $15 \mathrm{~m}$ beneath the profile. This could be attributed to weathering effect and lateritic gravel materials in the top layer. There is a protruded high resistivity $(>400 \Omega \mathrm{m})$ geological formation at the base designated A observed between 80 and $120 \mathrm{~m}$ beneath the profile. This was interpreted as fractured bedrock based on the geometry and the resistivity contrast with the surrounding formation.

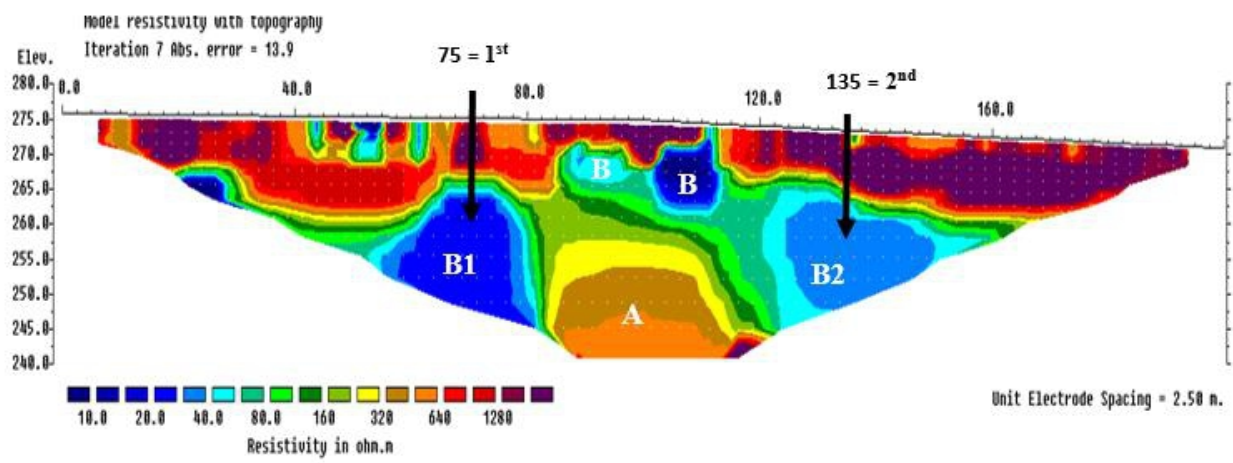

Figure 12. Resistivity model-section of Kuntuntadease profile 
The model-section further reveals portions of very low resistivity $(<40$ $\Omega \mathrm{m})$ zones designated $\mathbf{B}$ found at isolated places which could be interpreted as moist clayey material and hence not targeted for groundwater exploitation. The resistivity model-section shows zones of possible anomalies marked B1 and $\mathbf{B} 2$ of resistivity of about $40 \Omega \mathrm{m}$. These spotted anomalies, bounded by relatively high resistivity are interpreted as potential sites for groundwater reserve and possible sites for groundwater exploitation. The points A75 and A135 marked $1^{\text {st }}$ and $2^{\text {nd }}$ were selected for drilling in order of preference.

\section{Borehole drilling results}

Essentially, rock cuttings or chippings were periodically sampled for analysis during the drilling phase. The process helps in determining the lithological units of the subsurface layer, their thicknesses, nature and depth to the aquifer zones. Generally, the borehole logs revealed mostly five and occasionally four subsurface layers. The results of the borehole drill logs as shown in figure 13.0 also revealed that the aquifers zones were within weathered and fractured units, which were in agreement with the results of 2D CVES. Geologically, boreholes drilled in the study area were within sandstone, siltstone and phyllite granitic environments. Quantitatively, the drilling log results show that all the drilled wet wells have alternate two aquifer zones between 30 and $60 \mathrm{~m}$. However, only the Konkonti and Seikwa communities have their second relatively deeper aquifer zones extending slightly beyond $60 \mathrm{~m}$ at depth. The groundwater yields from the drilled boreholes within the study area varied between a minimum of 15 to a maximum 800 litres/min; and the average intercepted depth of aquifer was at about $30 \mathrm{~m}$ and below.

\section{Legend}

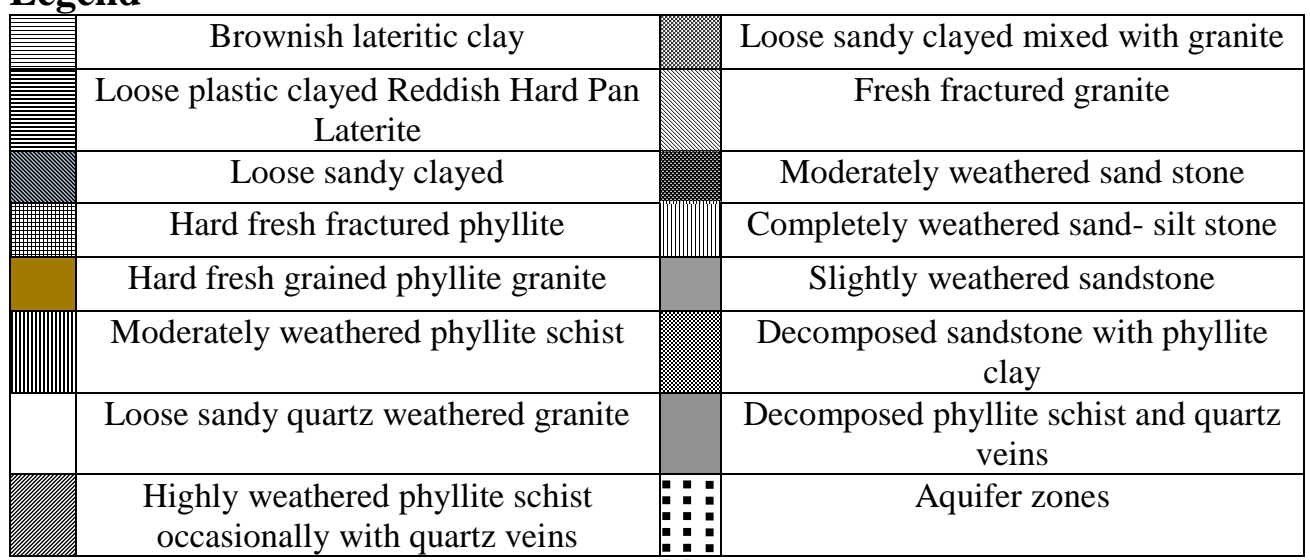

Figure 13. Lithological d̄rilling logs of Boreholes 


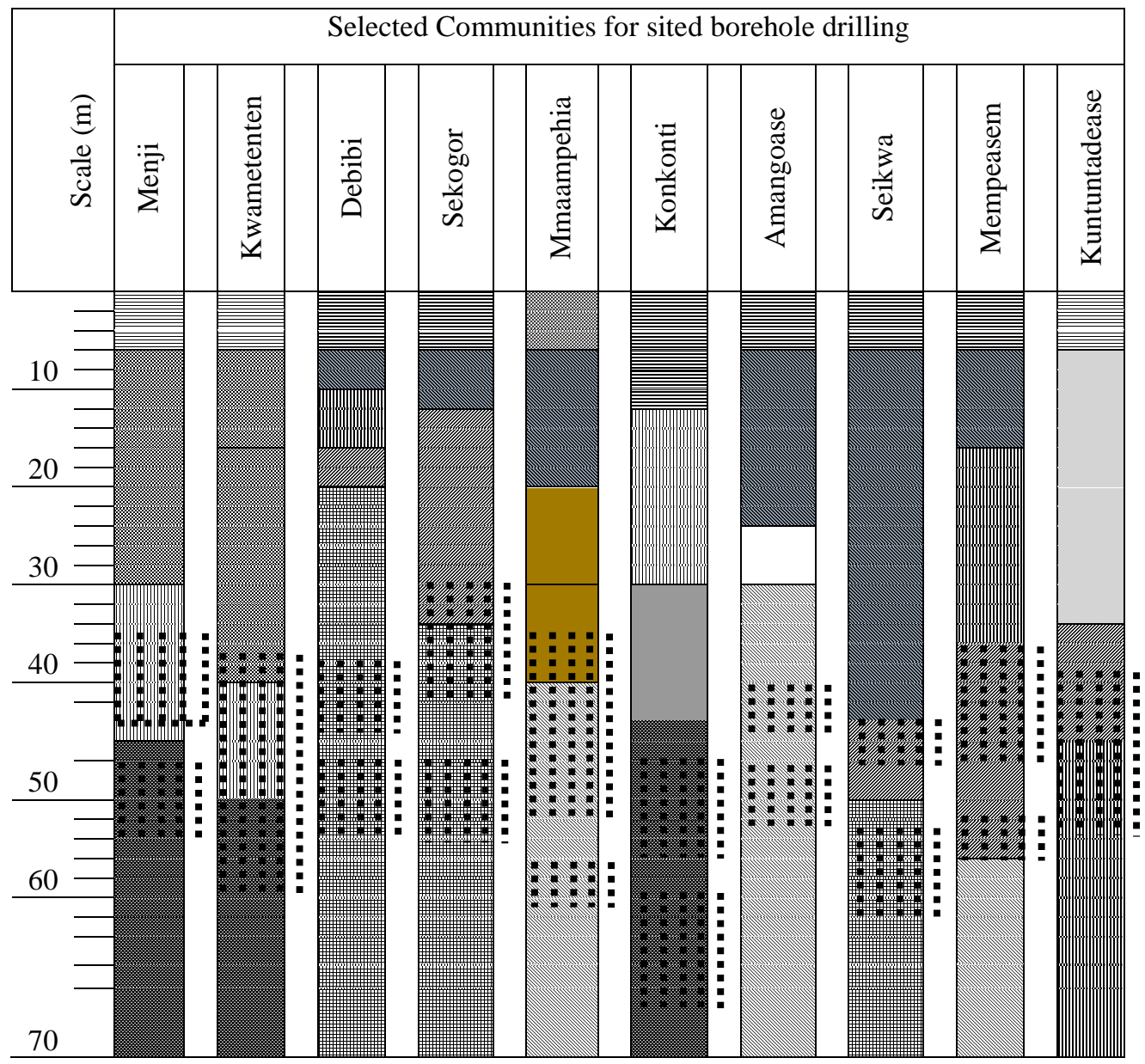

\section{Conclusion}

The CVES technique produced substantial 2-D model-sections with high quality in terms of structural resolution. This led to the demarcation of the layering of various lithological units; weathering layers, depth to bedrock and identification of important structures such as fractures and faults. These structures are quite significant in groundwater accumulation and exploration.

The 2-D resistivity model sections and the borehole drill logs of the various profiles in the study communities revealed that the geology of the area is underlain by highly-weathered, fractured and local faulted zones. The study has established that the rocks forming the aquifer in the Tain District in the Black Volta Basin comprise mainly of weathered overburden and fracturing of the underlying bedrock. It therefore suggests that the hydrogeology of the project area is highly complex since the accumulation and transmission of groundwater is generally due to secondary porosities. 
The variation in thicknesses and electrical resistivities of the various geological structures (anomaly) of the sub-surface are attributed to structural deformation and weathering. This is evidenced by the highly-heterogeneous nature of the subsurface rock materials and high weathering of the underlying bedrock. These do not only result from the metamorphosed nature of the Birimian and Tarkwaian rock formations, but also for the fact that the study area falls within geological contact zone between Birimian and Tarkwaian formations. Such areas are always characterised by high degree of frequent minor and major fractures, hence high degree of permeability. The thicknesses and resistivity values of the aquiferous zones relative to the background resistivities suggest that, these geological structures could be targets for groundwater occurrence. In selecting the drilling sites, much attention was placed on water-bearing structures located at deeper depth on the basis of the fact that basement formation plays a major role in striking sustainable and quality yield groundwater.

The borehole yields within the study area were between a minimum of 15 and maximum of 800 litres/min; and the mean depth of intercepting aquifer was about $30 \mathrm{~m}$.

\section{References:}

1. Amoako, J. A., 2008. Mapping Groundwater Quality in Northern Region of Ghana Using GIS.

2. MSc. Thesis (Kwame Nkrumah University of Science and Technology)

3. Aning, A. A., Tucholka, P. and Danuor, S. K., 2013. 2D Electrical Resistivity Tomography (ERT) Survey using the Multi-Electrode Gradient Array at the Bosumtwi Impact Crater, Ghana. Journal of Environment and Earth Science, Volume 3.

4. Anornul, G. K., Kabo-bah, A. T. and Anim-Gyampo, M., 2012. Evaluation of Groundwater Vulnerability in the Densu River Basin of Ghana. American Journal of Human Ecology, Volume 1, No. 3.

5. Dapaah-Siakwan, S. and Gyau-Boakye, P., 2000. Hydrogeological framework and borehole yields in Ghana. Hydrogeological Journal, pp. 400-416.

6. Dewashish, K., 2012. Efficacy of Electrical Resistivity Tomography Technique in Mapping Shallow Subsurface Anomaly. Journal Geological Society Of India, September.Volume Vol.80, pp.304-307.

7. Erdelyi, Research Institute for WaterResources, Budapest, Hungary, 2010. The hydrogeology of Ghana. Hydrological Sciences Journal, January . 
8. Geotomo Software, 2010. Geoelectrical Imaging 2D \& 3D Geotomo Software (RES2DINV ver. 3.59) manual. Minden Heights, 11700 Gelugor(Penang): s.n.

9. Gill, H. E., 1969. A Groundwater reconnaissance of the Republic of Ghana, with a description of geohydrologic provinces. Washington: National government publication.

10. Gyau-Boakye, P., Kankam-Yeboah, K., Dapaah-Siakwan, S. and Darko, P. K., 2008. Groundwater as vital resource for rural development: An example from Ghana. In: A. M. Segun Adelana, ed. Applied groundwater studies in Africa:Taylor \& Francis, pp. 149-170.

11. Heath, R. C., 1987. Basic Ground-Water Hydrology, North Carolina: United States Geological Survey.

12. Kortatsi, B., Tay, C. and Hayford, E., 2008. Hydrogeochemical evaluation of groundwater in the Lower Offin Basin of Ghana. Environmental Geology, Feb.Volume 53 (8).

13. Loke, M. H., 2000. Electrical imaging surveys forenvironmental and engineering studies, A practical guide to 2-D and 3-D surveys. s.1.:s.n.

14. Loke, M. H., 2010. Tutorial : 2-D and 3-D electrical imaging surveys.

15. Ratnakumari, Y., Rai, S. N., Thiagarajan, S. and Kumar, D., 2012. 2D Electrical resistivity imaging for delineation of deeper aquifers in a part of the Chandrabhaga river basin, Nagpur District, Maharashtra, India. Current sciennce, January.Volume 102, NO. 1.

16. Sabet, A. M., 1975. Vertical Electrical Resistivity soundings to Locateground Water resources: a feasibility study. Virginia Water Resources Research Center, Virginia Polytechnic Institute and State University.

17. Tain District Assembly, 2006. http://tain.ghanadistricts.gov.gh [Online] Available at: http://tain.ghanadistricts.gov.gh [Accessed 2013].

18. WHO, 2004. Guidelines for Drinking-water Quality, 20 Avenue Appia, 1211 Geneva 27, Switzerland: World Health Organization.

19. WHO, 2006. Groundwater and public health. In: G. Howard, et al. eds. Protecting groundwater for health: Managing the quality of drinkingwater sources. London: IWA Publishing, UK.

20. WHO, 2010. Guidelines for Drinking-water Quality, Geneva 27, Switzerland: World Health Organization, 20 Avenue Appia. 